\title{
TI.110.1
}

\section{Group and membership concepts}

- PDF: internet2-mace-dir-group-membership-200507.pdf

- HTML: internet2-mace-dir-group-membership-200507.html

\begin{tabular}{|c|c|}
\hline \multicolumn{2}{|c|}{ More Information } \\
\hline Repository ID & TI.110.1 \\
\hline Persistent URL & http://doi.org/10.26869/TI.110.1 \\
\hline Title & Group and membership concepts \\
\hline Authors & Keith Hazelton \\
\hline Sponsor & MACE \\
\hline \multicolumn{2}{|l|}{ Review } \\
\hline Status & Legacy \\
\hline Publish Date & July 5, 2005 \\
\hline DOI & 10.26869/TI.110.1 \\
\hline \multicolumn{2}{|l|}{ Signature } \\
\hline Deprecated & No \\
\hline \multicolumn{2}{|l|}{ Future Review } \\
\hline \multicolumn{2}{|l|}{ Supersedes } \\
\hline Format & PDF, HTML \\
\hline \multicolumn{2}{|l|}{ Related Docs } \\
\hline Development Location & memb-041107.jpg (graphic) \\
\hline \multicolumn{2}{|l|}{ IP Framework } \\
\hline Subject Tags & middlewarerescue \\
\hline Notes & \\
\hline
\end{tabular}

